dryness in a silica boat in a vacuum oven at $55^{\circ} \mathrm{C}$. The dry residue was combusted to carbon dioxide in a furnace and the carbon dioxide evolved collected in sodium hy. droxide and precipitated as barium carbonate. The radioactivity of the barium carbonate was determined by liquid scintillation counting after suspending it in a thixotropic gel-toluene counting solution. The reproducibility of this method was checked using ${ }^{14} \mathrm{C}$-glucose, uniformly labelled. From the results of 5 replicates, the standard error, expressed as a percentage of the mean, was $\pm 3 \cdot 6$.

Radioactivity first appeared in the exudate 4-5 h after the start of exposure of the tops to ${ }^{14} \mathrm{CO}_{2}$ and continued for the final period of collection of 24-48 h. The radioactivity of the exudates collected over a $48-\mathrm{h}$ period from roots in plant nutrient solution indicated that approximately 0.1 per cent of carbon-14 assimilated was exuded by the roots. The amount of exudate, as indicated by radioactivity, was increased when roots were immersed in distilled water rather than plant nutrient solution during the course of the experiment (Table 1). There are indications that exudation of ${ }^{14} \mathrm{C}$-labelled compounds from roots is affected by aeration of the roots-less radioactivity being exuded at low oxygen tensions. Several radioactive compounds were detected when paper chromatograms of the root exudates were examined by autoradiography.

Table 1. Exudation of Radioactivity bY WhEAT ROOTS IN WATER AND PLANT NUTRIENT SOLUTION

Distilled water Roots immersed in:

$\begin{array}{rr}7248^{*}(455) \dagger & 4570^{*}(610) \dagger\end{array}$

* Counts per $100 \mathrm{sec}$ in exudate from 2 plants over $15.5 \mathrm{~h}$.

This investigation has shown that labelled photosyn. thate can be used to trace the exudation of organic compounds from intact roots. Application of carbon-14 to the plant as ${ }^{14} \mathrm{CO}_{2}$ is considered superior to the application of labelled sugars or amino-acids to leaves or cut petioles, since the normal translocated materials of the plant become labelled and there is no danger of loading the plant with unrealistic concentrations of any particular compound, a factor which might alter exudation patterns.

The use of ${ }^{14} \mathrm{CO}_{2}$-treated plants for root exudate studies has been reported previously ${ }^{3,4}$, but the work recorded here has shown that the technique can be used for shortterm studies for which complete asepsis is unnecessary, measuring the exudation from individual plants and even from different portions of the same root. By growing plants in the presence of ${ }^{14} \mathrm{CO}_{2}$ for longer periods it may be possible to obtain equilibration of labelling in the plant and the radioactivity exuded should then yield quantitative data of exudate components.

Barbara M. McDougall C.S.I.R.O.

Division of Soils, Glen Osmond, South Australia.

1 Rovira, A. D. in The Ecology of Soil Borne Plant Pathogens-Prelude to Biological Control, edit. by Baker, K. F., 571 (Univ. Calif. Press, 1962).

2 Hoagland, D. R., and Arnon, D. I., Univ. Calif. Agric. Exp. Sta. Circ., 347 (1938).

s Slankis, V., Runeckles, V. C., and Krotkov, G., Physiol. Plant, 17, 301 (1964).

4 Subba-Rao, N. S., Bidwell, R. G. S., and Bailey, D. I., Canad. J. Bot., 40, 203 (1962).

\section{Method to study Germination of Fungus Spores in Soil}

VARIOUs methods have been devised to study the germination of fungus spores in the soil ${ }^{1,2}$. These methods have the disadvantage that the spores are held under conditions different from those in natural soil. Boosalis ${ }^{3}$ developed a method which eliminates the disadvantages of other methods but is rather cumbersome. The following method was found to be satisfactory for application in studies on soil-fungistasis and for determining the effect of various soil amendments on the germination of conidia of Helminthosporium sativum P.K. and B. in the soil.

The soil is air-dried and sieved through a $1-\mathrm{mm}$ mesh sieve to obtain a uniform maximum particle size. Both halves of a Petri dish are then filled with the soil and the surface of each levelled. To retain a smooth surface the soil is moistened by means of a spray gun operating at $5 \mathrm{lb} . / \mathrm{sq}$. in. Care must be taken not to blow holes in the soil surface by holding the spray gun too close to the soil. If an absolutely level surface is not required, the soil can be moistened by means of a pipette. The amount of water applied will be determined by the soil type and the nature of the test. The spores (in suspension) are applied by means of a pipette to the soil in the lid part of the Petri dish (Fig. 1). The number of spores must be sufficient to permit easy recovery after incubation. A disk of plastic or nylon mesh (approx. $2 \mathrm{~mm}$ ), with a diameter similar to that of the Petri dish, is placed on the other half and pressed down firmly. The purpose of the mesh is to separate the soil surfaces and yet provide contact and air spaces. The Petri dish is then assembled as indicated in Fig. 1 and the two parts lightly pressed together to ensure contact between the soil surfaces. It is then incubated under conditions suitable for the germination of the spores.

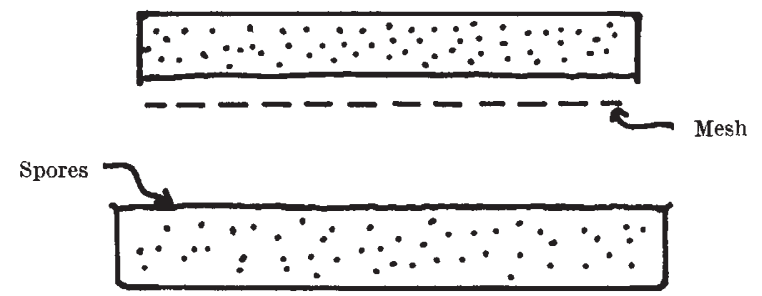

Fig. 1. Diagrammatic representation of Petri-dish assembly for tests of spore germination in the soil

After incubation, the two parts of the Petri dish are separated carefully, and a spore print is made with an agar strip $^{3}$ which is examined microscopically. The agar strips can also be incubated in a moist chamber to determine the viability of ungerminated spores.

Agricultural Research Institute,

W. J. Jooste

Potchefstroom, South Africa.

${ }^{1}$ Chinn, S. H. F., Canad. J. Botany, 31, 718 (1953).

2 Dobbs, C. G., Hinson, W. H., and Bywater, Joan, The Ecology of Soil Fungi (Liverpool University Press, Liverpool, 1960).

${ }^{3}$ Boosalis, M. G., Phytopathology, 50, 860 (1960).

\section{Male and Female Influence of Adult Individuals on Undifferentiated Larvae of the Parasitic Nematode Paramermis contorta}

Previous experimental infestations of Chironomus tentans larvae with the nematode Paramermis contorta confirmed that crowding plays a major part in determining the sex of the parasites ${ }^{1}$. Observations by Caullery and Comas $^{2}$ on natural populations showed that an increase of the degree of infestation results in an increase of the relative frequency of the males of Paramermis. It was also established that, at a given degree of infestation, the relative frequency of male Paramermis decreases with the increasing lengths of the Chironomus larvae at the moment when they are penetrated by the nematode ${ }^{3}$.

Work has now been carried out in order to establish whether, in cases of two successive infestations, the individuals which develop first in the haemocoele of the host can influence the sexual differentiation of the young individuals that penetrate successively the Chironomus larva.

About 4,000 larvae parasitized by a single nematode were obtained from about 10,000 larvae of Chironomus 